04

\title{
Разрядная система с самонакаливаемым полым катодом и испаряемым анодом в остроугольном магнитном поле для нанесения оксидных покрытий
}

\author{
(C) Н.В. Гаврилов, ${ }^{1}$ А.С. Каменецких, ${ }^{1}$ Д.Р. Емлин, ${ }^{1}$ П.В. Третников, ${ }^{1}$ А.В. Чукин ${ }^{2}$ \\ ${ }^{1}$ Институт электрофизики УрО РАН, \\ 620016 Екатеринбург, Россия \\ 2 Уральский федеральный университет, \\ 620002 Екатеринбург, Россия \\ e-mail: gavrilov@iep.uran.ru
}

Поступило в Редакцию 1 июня 2018г.

В окончательной редакции 1 июня 2018г.

Принято к публикации 18 декабря 2018г.

\begin{abstract}
Исследованы свойства разряда с самонакаливаемым полым катодом и испаряемым анодом, помещенными в остроугольное магнитное поле, создаваемое двумя встречно включенными катушками, установленными в области анода и катода. В области кольцевой магнитной щели установлен отрицательно смещенный держатель образцов. Сжатие столба разряда на аноде магнитным полем обеспечивает эффективное испарение металла (алюминий), загружаемого в анод-тигель, изменением тока катодной магнитной катушки регулировалось плотность генерируемой в объеме кислородсодержащей плазмы. Скорость нанесение покрытий из оксида алюминия реактивным анодным испарением в отличие от реактивного магнетронного распыления не ограничена окислением распыляемой мишени, ресурс термоэмиссионного катода составляет сотни часов. Высокая плотность ионного тока из плазмы (до $10 \mathrm{~mA} / \mathrm{cm}^{2}$ ) обеспечивает снижение температуры кристаллизации и формирование нанокристаллических оксидных покрытий. Определены условия стабильного горения разряда с током до 40 А при давлении кислородно-аргоновой смеси $0.1 \mathrm{~Pa}$. Приведены результаты зондовой диагностики параметров плазмы разряда, измерения скорости осаждения, анализа структуры и свойств покрытий из оксида алюминия.
\end{abstract}

DOI: 10.21883/JTF.2019.06.47632.214-18

\section{Введение}

Метод реактивного испарения способен обеспечить более высокую скорость осаждения и качество непроводящих тонких пленок оксидов металлов по сравнению с методом реактивного ионного распыления. Как известно, образование оксидного слоя на поверхности распыляемой мишени снижает скорость распыления, а накопление поверхностного заряда и пробои слоя являются причиной дугообразования, ухудшающего качество наносимых покрытий [1].

Высокие скорости испарения металлов, в частности алюминия, обеспечиваются электронно-лучевым методом [2], известный недостаток которого заключается в сравнительно низкой доле ионизированных частиц в общем потоке испаряемого материала, что влияет на прочность адгезионной связи осаждаемых покрытий с подложкой. Для улучшения адгезии получаемых таким методом покрытий и снижения температуры кристаллизации оксидных пленок применяют вспомогательные сильноточные разряды, создающие интенсивные потоки ионов на поверхность растущего покрытия [3]. Однако необходимость использования высоковольтных электронных пушек, генерирующих рентгеновское излучение и требующих применения высоковакуумных систем откачки, ограничивает применение этого метода. Вы- сокоскоростное испарение металлов достигается также в дуговых разрядах. Известным недостатком катодной дуги является генерация в катодных пятнах микрокапель, размер которых может быть сопоставим с толщиной оксидного покрытия [4]. Дуговые разряды в парах материала анода являются источниками бескапельных потоков, которые способны обеспечить высокую степень ионизации металлического пара [5]. Наиболее широко для этих целей используют разряд с термоэмиссионным катодом [6], однако получение оксидных покрытий в таком разряде затруднено из-за резкого снижения ресурса накаливаемого катода [7]. Применение для этой цели дуги с катодными пятнами на холодном катоде нежелательно из-за влияния паров материала катода на состав и характеристики плазмы [8].

Для генерации кислородсодержащей плазмы в процессе реактивного электронно- лучевого осаждения пленок оксида алюминия успешно используется самостоятельный разряд с самонакаливаемым полым катодом в потоке инертного газа [3]. Длительную работоспособность накаливаемого катода обеспечивает газодинамический барьер для атомов кислорода, создаваемый потоком инертного газа через катодную полость малого сечения. Значительная (0.6-0.8) доля мощности, выделяющейся на аноде разряда, от полной мощности, рассеиваемой в разряде, и высокая плотность мощности на аноде 
(до $10^{5} \mathrm{~W} / \mathrm{cm}^{2}$ ) при малых межэлектродных зазорах $(1-5 \mathrm{~cm})$ позволила использовать такой разряд для плавки и сварки металлов [9]. Однако для нанесения оксидных покрытий на большие поверхности в системе с соосным расположением катода и анода необходимо увеличивать длину межэлектродного зазора, что приводит к падению плотности мощности на аноде и снижению скорости испарения металла. Кроме того, в такой электродной системе отсутствует возможность независимого изменения скорости испарения металла и плотности ионного потока из плазмы.

Ранее авторами было показано, что для снижения температуры получения таким методом покрытия, состоящего из альфа-фазы оксида алюминия, необходимо обеспечивать определенные параметры ионного потока $\left(2-8 \mathrm{~mA} / \mathrm{cm}^{2}, 25-200 \mathrm{eV}\right)$, что достигалось применением сильноточного (до $30 \mathrm{~A}$ ) разряда на вспомогательный трубчатый анод, через который в систему напускался кислород $[10,11]$. Для повышения надежности системы в настоящей работе был использован водоохлаждаемый анод-тигель, что привело к значительному увеличению тепловых потерь и необходимости повышения мощности, подводимой к аноду-тиглю. Применение остроугольного магнитного поля, создаваемого встречно включенными короткими магнитными катушками, установленными на катоде и аноде разрядной системы, позволило решить целый ряд проблем. Сжатие столба разряда в криволинейном магнитном поле анодной катушки обеспечило увеличение плотности мощности на удаленно расположенном аноде, а изменение конфигурации магнитного поля в разрядном промежутке включением катодной катушки позволило увеличить плотность плазмы и регулировать ее в широких пределах изменением величины тока катушки. Размещение отрицательно смещенного держателя образцов в области кольцевой магнитной щели обеспечивает эффективный отбор ионов из плазмы. В целом конструкция такой разрядной системы аналогична конструкции однощелевой электромагнитной ловушки типа антипробкотрона [12] с той разницей, что анодная магнитная щель открыта для стока электронов.

Целью исследований являлось изучение условий стабильного горения разряда с самонакаливаемым полым катодом и удаленно расположенным испаряемым анодом, помещенным в остроугольное магнитное поле, диагностика параметров плазмы разряда, измерение скорости осаждения и исследование свойств покрытий из оксида алюминия.

\section{Методика эксперимента}

Схема эксперимента показана на рис. 1. Трубчатый полый катод 1 и анод-тигель 2 помещены в остроугольное магнитное поле, создаваемое встречно включенными короткими магнитными катушками 3 и 4. В области кольцевой магнитной щели на расстоянии $\sim 10 \mathrm{~cm}$ от

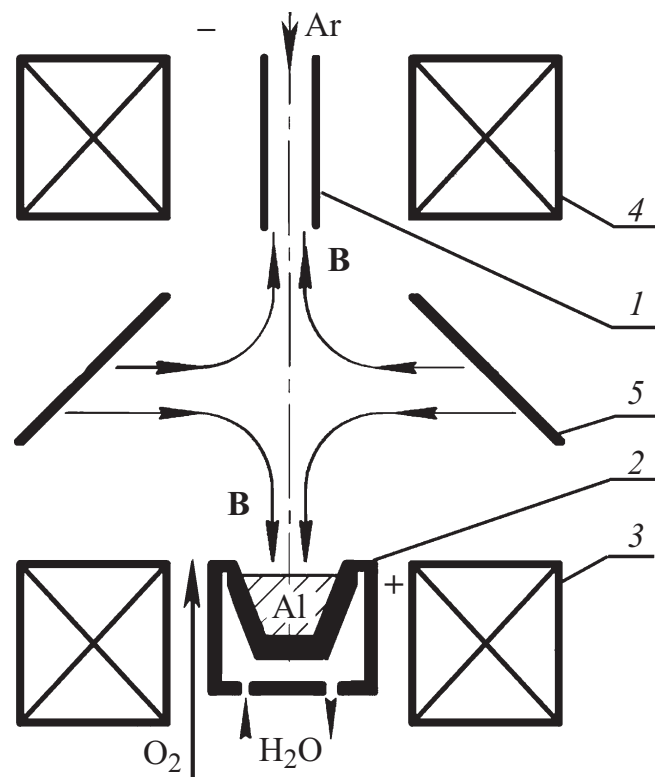

Рис. 1. Схема эксперимента: 1 - полый катод, $2-$ анодтигель, 3,4 - магнитные катушки, 5 - держатель образцов.

анода-тигля установлен держатель образцов 5, нормаль к плоскости которого составляет $\sim 45^{\circ}$ относительно оси разрядной системы. Максимальная индукция поля, создаваемого катушками, достигает $20 \mathrm{mT}$ при токах катушек $10 \mathrm{~A}$ (катушка 3) и 20 А (катушка 4). Такая комбинация остроугольного магнитного поля с частичным электростатическим запиранием магнитных щелей обеспечивает повышенную эффективность ионизации газа в объеме. Через катодную полость подавался аргон $(10-20 \mathrm{sccm})$, кислород (30 sccm) поступал в анодную область разряда. Водоохлаждаемый тигель изготовлен из нержавеющей стали, диаметр и глубина полости, в которую загружаются гранулы алюминия, составляют 25 и $10 \mathrm{~mm}$ соответственно.

В экспериментах использовался катодный узел, представленный на рис. 2. В молибденовом держателе 1 диаметром $16 \mathrm{~mm}$ и длиной $105 \mathrm{~mm}$ выполнен канал диаметром $10 \mathrm{~mm}$, разделенный на две части графитовой вставкой 2 с узким каналом $2 \times 10 \mathrm{~mm}$. В нижней части канала установлена термоэмиссионная трубчатая вставка 3 из нитрида титана длиной $60 \mathrm{~mm} \mathrm{c}$ внутренним диаметром $8 \mathrm{~mm}$, изготовленная методом магнитно-импульсного прессования [13]. Верхняя часть канала плотно заполнялась отрезками вольфрамовой проволоки, что исключало возникновение разряда в этой области. Молибденовый держатель посредством резьбового соединения через медное уплотнение крепился к водоохлаждаемому фланцу 4 и размещался внутри водоохлаждаемой обечайки 5 соосно с тепловым экраном 6, изготовленным из графита или ниобия. Снаружи обечайки установлена катодная магнитная катушка. Разработанная конструкция катодного узла обеспечивает надежный контакт при токах в десятки А, зажигание 


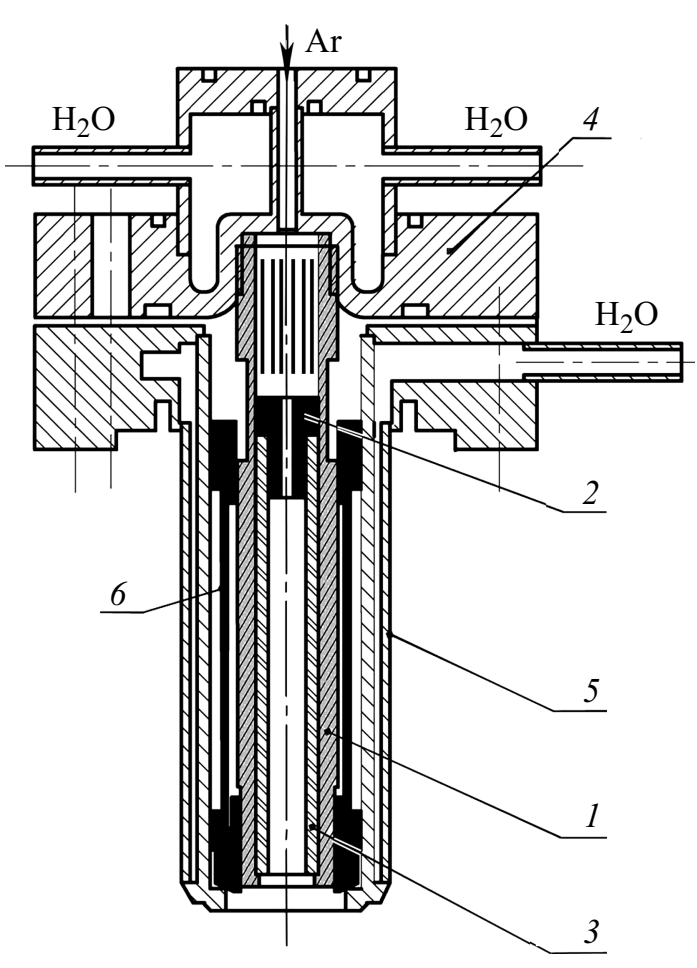

Рис. 2. Катодный узел: 1 - молибденовый держатель, $2-$ графитовая вставка, 3 - термоэмиссионная TiN вставка, 4 фланец, 5 - корпус, 6 - тепловой экран.

тлеющего разряда в области повышенного давления газа вблизи узкого канала, локальный разогрев катода и последующее формирование активной зоны на поверхности эмиссионной вставки из нитрида титана, а также исключает протекание рабочего газа вне катодной полости. Для сокращения тепловых потерь уменьшено поперечное сечение молибденового держателя в его верхней части. Калориметрическими измерениями установлено, что суммарные потери мощности в результате теплоотвода вдоль стержня и излучения с боковой поверхности катода не превышают $300 \mathrm{~W}$ в режиме горения разряда с током 30 А при напряжении горения $60 \mathrm{~V}$.

Вакуумная откачка производилась турбомолекулярным насосом, рабочее давление газовой смеси составляло $\sim 0.1 \mathrm{~Pa}$.

Стартовый нагрев полого катода производился газоразрядным методом: вначале в катодной полости зажигался тлеющий разряд, который при регулируемом увеличении тока переходил в аномальный режим горения, а затем в дуговой разряд с распределенной термоэмиссией [14]. Падающая вольт-амперная характеристика источника питания разряда обеспечивала снижение напряжения горения разряда на стадии перехода в дугу. Особенностью примененного метода стартового нагрева является импульсно- периодический режим горения тлеющего разряда с регулируемым амплитудным током 5-30 А при длительности импульсов несколько $\mu \mathrm{s}$. Такой режим обеспечивал эффективную тренировку поверхности катода и ограниченное энерговыделение при возникновении локальных привязок дуги на стадии запуска катода, что способствовало уменьшению эрозионного износа катода в процессе старта. При средней мощности импульсно- периодического источника питания $1 \mathrm{~kW}$ время выхода катода на термоэмиссионный режим горения со средним током разряда $10 \mathrm{~A}$ составляло $15-20 \mathrm{~s}$.

Разряд горел в потоке аргона, минимальная величина которого, обеспечивающая устойчивое горение разряда с током $40 \mathrm{~A}$, составляет $10 \mathrm{sccm}$. Разряд имеет падающую вольт-амперную характеристику, напряжение горения разряда с катодом из нитрида титана при токе $40 \mathrm{~A}$ составляет 50-60 V.

Профили плотности тока электронов и плавающий потенциал зонда измерялись с использованием подвижного ленгмюровского зонда, который перемещался по круговой траектории, проходящей через ось разрядной системы на различных расстояниях от анода. Зонд был изготовлен из молибденовой проволоки диаметром $0.2-2 \mathrm{~mm}$, длина открытой части зонда составляла $10 \mathrm{~mm}$. Зависимости плотности ионного тока от тока разряда и тока магнитных катушек измерялись непосредственно в области размещения держателя образцов. Нагреватель, расположенный с тыльной стороны держателя образцов, обеспечивал радиационный нагрев образцов в процессе осаждения пленок до температуры $620^{\circ} \mathrm{C}$.

Микротвердость пленок определяли ультрамикротвердометром DUH-211/211S (Shimadzu), толщину пленок измеряли методом абразивного шарового истирания на приборе „Calotest“, (CSM Instruments), рентгенофазовый анализ проводили с использованием дифрактометра XRD-7000 (Shimadzu).

\section{Результаты эксперимента}

На рис. 3 показаны радиальные профили электронного тока на зонд, имеющий потенциал анода и перемещающийся в плоскости, отстоящей от анода на $10 \mathrm{~mm}$. Профили получены при токе разряда $40 \mathrm{~A}$, токах анодной катушки 0 и $10 \mathrm{~A}$, токе катодной катушки 0 А в условиях интенсивного испарения алюминия. Полная ширина на половине высоты профилей при наложении магнитного поля уменьшается с 7.5 до $2.5 \mathrm{~mm}$, поперечное сечение столба разряда при этом сокращается почти на порядок величины. Присутствие металлических паров обеспечивает сжатие столба разряда при всех значениях тока разряда. В отсутствие паров металла магнитное поле эффективно сжимает электронный поток только при относительно малых токах разряда $\sim 10$ А, при больших токах влияния магнитного поля не наблюдается.

Величина плавающего потенциала зонда (рис. 4) зависит от тока разряда, индукции магнитного поля и наличия паров металла. Плавающий потенциал зонда 


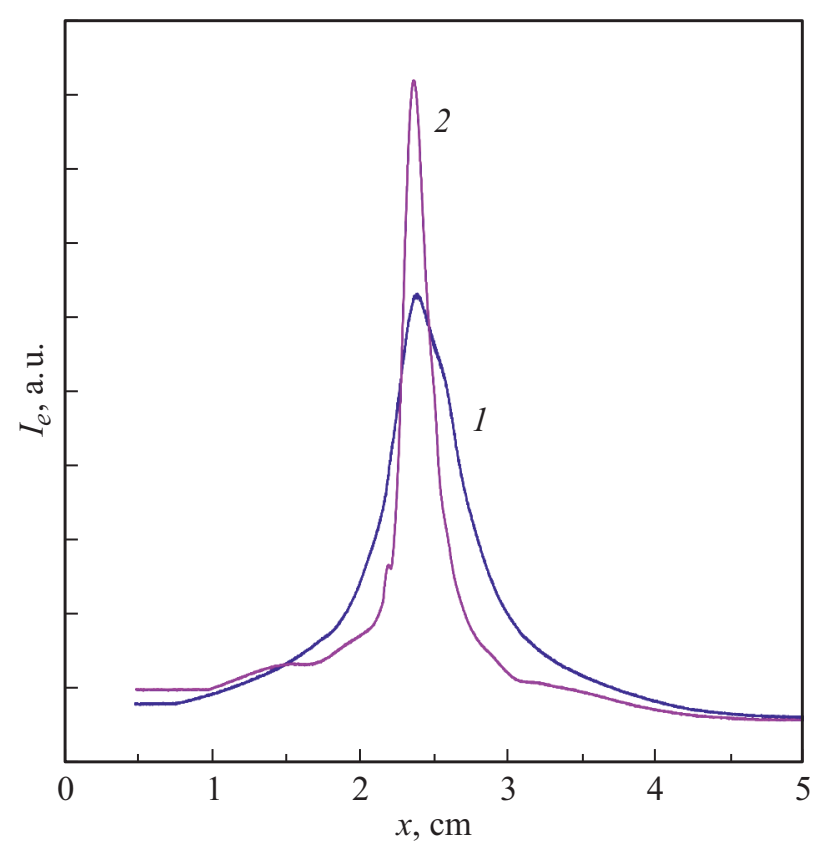

Рис. 3. Радиальные распределения электронного тока. Ток анодной катушки: $1-0,2-10 \mathrm{~A}$. Расстояние от плоскости анода $10 \mathrm{~mm}$. Ток разряда $40 \mathrm{~A}$.

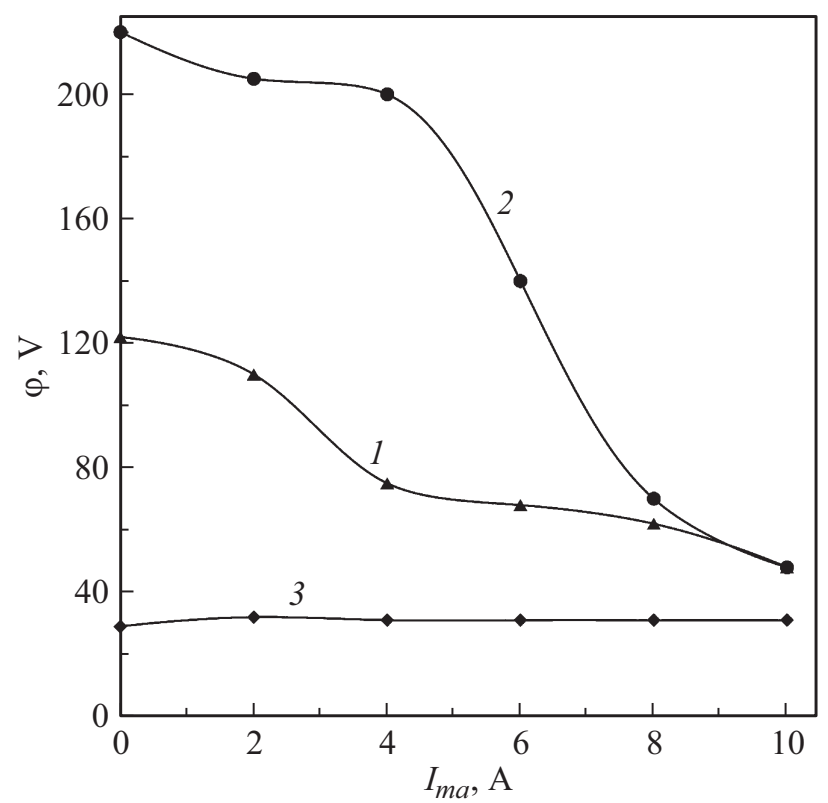

Pис. 4. Зависимости амплитуды колебаний плавающего потенциала зонда в разряде с неиспаряющимся $(1,2)$ и испаряющимся (3) анодом от тока анодной катушки. Ток разряда: $1-10$; $2,3-40 \mathrm{~A}$.

на оси разряда при отсутствии паров металла модулирован ионно-звуковыми колебаниями $(30-120 \mathrm{kHz})$, амплитуда которых с ростом тока разряда свыше $10 \mathrm{~A}$ возрастает до $220 \mathrm{~V}$. С ростом тока анодной катушки до 10 А амплитуда колебаний снижается до $\sim 20 \mathrm{~V}$ при токе разряда 40 A. В режиме испарения алюминия при токах разряда свыше $20 \mathrm{~A}$ колебания потенциала на оси отсутствуют, при токе разряда $40 \mathrm{~A}$ плавающий потенциал составлял около $-30 \mathrm{~V}$. Вне плазменного столба плавающий потенциал зонда на несколько вольт ниже, чем на оси разряда.

Зависимость средней плотности тока ионов аргона от тока катодной катушки при максимальном токе анодной катушки (10 A) на держатель образцов, расположенный на расстоянии от анода $100 \mathrm{~mm}$, представлены на рис. 5. На держатель образцов подавалось импульсное отрицательное напряжение смещения $(-100 \mathrm{~V}, 50 \mathrm{kHz})$. $\mathrm{C}$ ростом тока катодной катушки от 5 до 19 А средняя

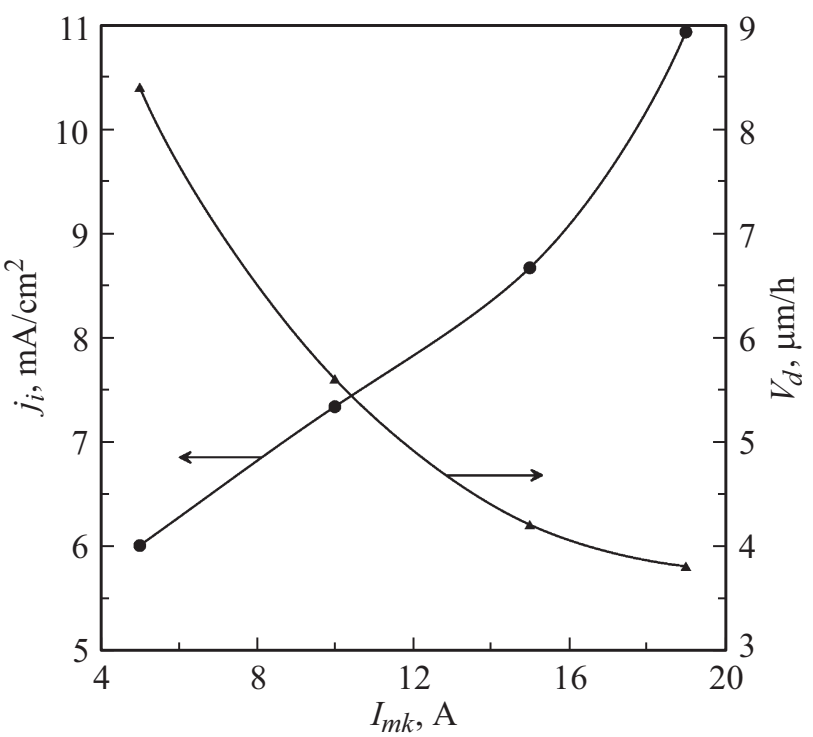

Рис. 5. Зависимости средней плотности ионного тока $\left(j_{i}\right)$ и скорости роста покрытия $\left(V_{d}\right)$ от тока катодной катушки. Ток разряда $40 \mathrm{~A}$. Ток анодной катушки $10 \mathrm{~A}$.

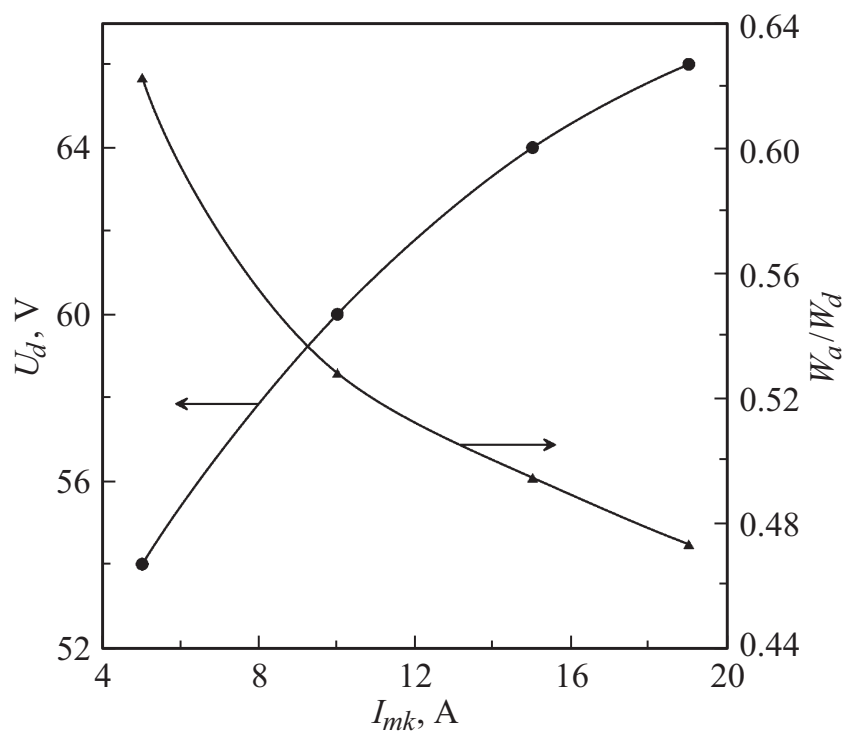

Рис. 6. Зависимости напряжения горения разряда и доли мощности разряда, выделяющейся на аноде от тока катодной катушки. Ток разряда $40 \mathrm{~A}$. Ток анодной катушки $10 \mathrm{~A}$. 


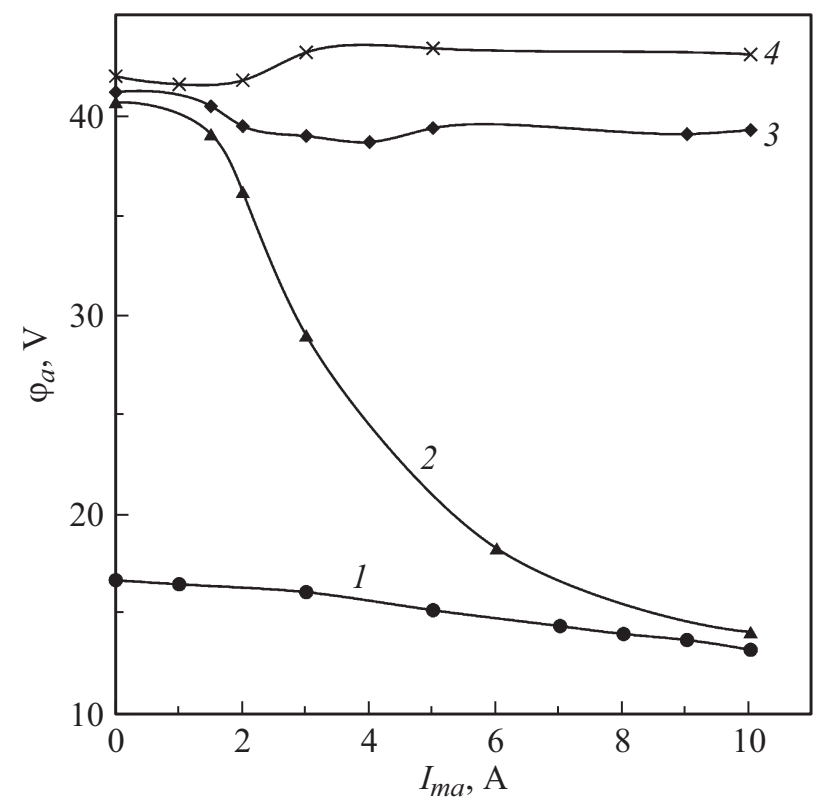

Рис. 7. Зависимости продольного падения потенциала в столбе от тока анодной катушки. Ток разряда: $1-10,2-$ $20,3-30,4-40 \mathrm{~A}$.

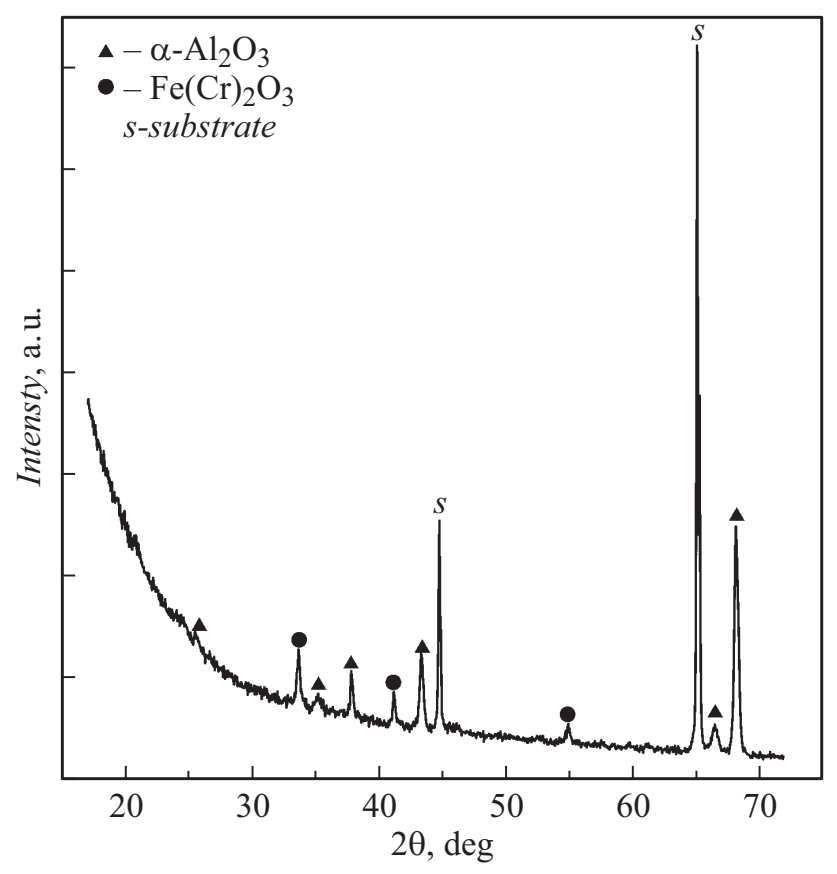

Рис. 8. Дифактограмма $\mathrm{Al}_{2} \mathrm{O}_{3}$ покрытия. Ток анодной катушки $10 \mathrm{~A}$, ток катодной катушки $15 \mathrm{~A}$.

плотность ионного тока возрастает до $11 \mathrm{~mA} / \mathrm{cm}^{2}$, амплитудное значение было примерно вдвое выше. Наряду с ростом плотности ионного тока снижается скорость роста покрытия. Напряжение горения разряда с ростом тока анодной катушки возрастает с 54 до $66 \mathrm{~V}$ (рис. 6), а доля мощности $W_{a} / W_{d}$, выделяющейся на аноде, при этом снижается с 0.62 до 0.49 . Величина $W_{a}$ измеря- лась калориметрическим методом, полная мощность $W_{d}$ рассчитывалась, исходя из измеренных значений тока и напряжения горения разряда. В то время, как мощность на аноде с ростом магнитного поля практически не меняется, полная мощность в разряде возрастает на 480 W. Как следует из полученных результатов, усиление магнитного поля в катодной части разряда приводит к увеличению энергозатрат на взаимодействие электронов с газом и росту плотности ионного тока. Значительное снижение скорости роста покрытия при практически неизменной мощности, выделяющейся на аноде, можно объяснить одновременным действием двух факторов: уменьшением плотности мощности на аноде вследствие большего рассеяния потока электронов и усилением ионного распыления покрытия вследствие более чем двукратного роста плотности ионного тока.

Изменение потока аргона в пределах 10-50 sccm практически не влияет на плотность тока ионов из плазмы.

Измерения продольного падения потенциала в столбе разряда проводились методом двойного зонда в отсутствие паров металла, при этом один зонд устанавливался в полости анода, а второй размещался на удалении $100 \mathrm{~mm}$ по оси разряда. В отсутствие магнитного поля измеренная разность потенциалов составила немногим более $40 \mathrm{~V}$ при токах разряда 20-40 А (рис. 7). Изменение разности потенциалов с ростом поля анодной катушки зависело от тока разряда: при малых токах $(10 \mathrm{~A})$ разность потенциалов минимальна $(\sim 15 \mathrm{~V})$, при токе разряда $20 \mathrm{~A}$ разность потенциалов между зондами с ростом поля уменьшалась с 41 до $14 \mathrm{~V}$, при больших токах оставалась практически неизменной $(\sim 40 \mathrm{~V})$.

Оценка температуры электронов проводилась по углу наклона прямолинейного участка вольт-амперной характеристики холодного собирающего зонда в полулогарифмическом масштабе. Измерения в слабых магнитных полях с загруженным алюминием тиглем показали, что с ростом тока разряда от 10 до $40 \mathrm{~A}$ температура электронов уменьшается от $\sim 6$ до $\sim 4 \mathrm{eV}$.

Зона расплава алюминия имела диаметр 6-8 $\mathrm{mm}$, в процессе испарения поверхность расплава была стабильна, всплесков и выбросов жидкого металла не происходило.

Нанесение пленки оксида алюминия производилось на образцы из нержавеющей стали $12 \mathrm{X} 18 \mathrm{H} 10 \mathrm{~T}$ с подслоем из оксида хрома толщиной $0.1 \mu \mathrm{m}$ при температуре $620^{\circ} \mathrm{C}$, токе разряда $40 \mathrm{~A}$, напряжении смещения $-100 \mathrm{~V}$. Средняя плотность ионного тока регулировалась в пределах 5-10 mA/ $\mathrm{cm}^{2}$, потоки кислорода и аргона составляли 20 и $50 \mathrm{sccm}$ соответственно. Скорость осаждения покрытия в таких условиях составляла $3.8-8.4 \mu \mathrm{m} / \mathrm{h}$. Были получены покрытия толщиной до $5 \mu \mathrm{m} \mathrm{c} \mathrm{твердо-}$ стью 20-24 GPa. На рис. 8 приведена дифрактограмма покрытия, содержащая пики, характерные для альфафазы A12O3, размер кристаллитов которой, оцененный методом Ритвельда, составляет $46 \mathrm{~nm}$. 


\section{Обсуждение результатов}

Возникновение ионно-звуковых колебаний потенциала плазмы и тока характерно для разряда с самонакаливаемым полым катодом, причем в разряде с импрегнированной катодной вставкой, работающей при низких температурах [15], увеличение тока при неизменном потоке газа приводило к раскачке интенсивных колебаний потенциала плазмы, тогда как в разряде с металлическим катодом [9] рост тока свыше $60 \mathrm{~A}$, напротив, стабилизировал разряд. Наиболее вероятной причиной наблюдавшихся различий является существенное повышение давления в коротком промежутке в результате испарения металлического анода. В наших экспериментах любое изменение условий, приводящее к увеличению потока ионов в катодную полость, например, повышение тока разряда с TiN катодом свыше 20 A, сжатие столба разряда магнитным полем в прианодной области и появление в разрядном промежутке паров металла, способствовало стабилизации разряда.

Сжатие столба разряда в криволинейном магнитном поле обусловлено тем, что в условиях, когда величина ларморовского радиуса электронов и шаг винтовой траектории значительно меньше размеров области неоднородности поля, движение электрона в магнитном поле представляет суперпозицию ларморовского вращения электронов, направленного движения вдоль линии магнитного поля и азимутального дрейфа поперек магнитного поля [16]. Величина ларморовского радиуса электрона с тепловой энергией $\sim 5 \mathrm{eV}$ в поле с индукцией $20 \mathrm{mT}$ составляет около $0.4 \mathrm{~mm}$.

Важнейшим параметром дуги с испаряемым анодом является тепловой поток из плазмы разряда на анод, для оценки которого в широком диапазоне изменения тока разряда используют вольтов эквивалент, определяемый отношением выделяющейся на аноде мощности $W_{a}$ к току в цепи анода I. Мощность, выделяющаяся на аноде разряда, определяется соотношением

$$
W_{a}=I\left(U a+\phi+2 k T_{e} / e\right)
$$

где $U_{a}$ - положительное анодное падение потенциала, $\phi-$ работа выхода материала катода, $2 k T_{e}-$ средняя энергия, которую термализованный электрон уносит на анод. Измерения, проведенные в работе, посвященной изучению вакуумных дуг с диффузным замыканием тока на испаряющихся горячих анодах [8], показали, что величина вольтова эквивалента с точностью до работы выхода материала анода равна величине прианодного падения потенциала $U_{a}$. Напротив, в дуге с самонакаливаемым полым катодом, распределение электронов по энергиям в плазме которой значительно отличалось от максвелловского, нагрев анода обеспечивался преимущественно электронами из высокоэнергетической части спектра [9]. Значительная доля быстрых электронов в спектре учитывалась введением соответствующего коэффициента в соотношении для анодной мощности перед величиной $2 k T_{e} / e$. С ростом тока от 60 до $150 \mathrm{~A}$ этот коэффициент возрастал от 1 до 3. При относительно низких напряжениях горения дуги (менее $20 \mathrm{~V}$ ) высокая температура плазменных электронов $\sim 6 \mathrm{eV}$ и наличие значительной направленной скорости электронов обеспечивают выделение на аноде $0.7-0.86$ от полной энергии без формирования положительного анодного падения.

В условиях эксперимента (рис. 6) вольтов эквивалент, оцененный из величины мощности, отводимой водой, без учета затрат энергии на испарение металла и радиационных потерь составлял $\sim 32 \mathrm{~V}$. Исходя из температуры плазменных электронов $\sim 4 \mathrm{eV}$, величины работы выхода электронов для алюминия $4.2 \mathrm{eV}$ и вольтова эквивалента мощности из соотношения для энергии, выделяющейся на аноде разряда, можно получить оценочную величину анодного падения $\sim 20 \mathrm{~V}$.

Другая оценка основывается на известной величине плавающего потенциала зонда относительно анода $(\varphi \sim 30 \mathrm{~V})$ и температуры электронов $(k T e \sim 4 \mathrm{eV})$. Предполагая, что вблизи испаряемого анода плазма содержит преимущественно ионы алюминия, из известного соотношения для плавающего потенциала относительно плазмы $e \varphi_{f p} / k T e \sim \ln \left[\left(0.77(M / m)^{1 / 2}\right][16]\right.$ получим $е \varphi \sim 5 k T e=20 \mathrm{eV}$, отсюда положительное анодное падение потенциала $U_{a}=\varphi-\varphi_{f p}$ составляет $\sim 10 \mathrm{~V}$. Таким образом, принимая во внимание значительную погрешность зондовых измерений в магнитном поле, на основании проведенных грубых оценок можно сделать вывод о существовании в исследуемом разряде положительного анодного падения потенциала величиной $\sim 10-20 \mathrm{~V}$. Измерения продольного падения потенциала в анодной части столба разряда (рис. 7) показывают, что с ростом тока разряда анодное падение возрастает, что обусловлено затрудненным замыканием тока электронов на анод, однако, в режиме испарения металла, напротив, следует ожидать снижения анодного падения с ростом током разряда.

Рост плотности ионного тока и уменьшение скорости осаждения покрытия при усилении магнитного поля (рис. 5) приводят к тому, что величина, характеризующая интенсивность ионного сопровождения, которая определяется отношением флюенса ионов $F$ к полному числу частиц $N$ в покрытии единичной площади, с ростом магнитного поля увеличивается с 0.4 до 1.5 . В [11] было показано, что для формирования нанокристаллической однофазной структуры пленки альфаоксида алюминия при пониженной температуре $\left(600^{\circ} \mathrm{C}\right)$ необходимо обеспечить определенные значения плотности ионного тока $\left(2-8 \mathrm{~mA} / \mathrm{cm}^{2}\right)$ и энергии ионов $(25-250 \mathrm{eV})$ на поверхности растущей пленки, при этом отношение ионного флюенса $F$ к числу частиц $N$, формирующих покрытие единичной площади, должно составлять $\sim(1-2)$. Достигнутые значения плотности ионного тока обеспечивают формирование покрытий из альфа-фазы оксида алюминия со скоростью 4-6 $\mathrm{m} / \mathrm{h}$, что было подтверждено в эксперименте. 


\section{Заключение}

Дуговой разряд с самонакаливаемым полым катодом в потоке инертного газа способен длительно генерировать плотную кислородсодержащую плазму и одновременно испарять материал анода. Это позволяет реализовать метод нанесения оксидных покрытий, скорость формирования которых в отличие от метода осаждения магнетронным распылением не ограничивается окислением распыляемой мишени, интенсивная ионная бомбардировка поверхности растущего покрытия позволяет значительно улучшить качество покрытий и снизить температуру их кристаллизации. Разряд в осесимметричном остроугольном магнитном поле обеспечивает высокую плотность мощности на поверхности анодатигля в результате сжатия столба разряда криволинейным магнитным полем (до $1 \mathrm{~kW} / \mathrm{cm}^{2}$ ), а также высокую плотность плазмы в объеме и возможность регулировки в широких пределах $\left(5-10 \mathrm{~mA} / \mathrm{cm}^{2}\right)$ плотности тока ионов из плазмы на поверхность растущего покрытия. Достигнуто стабильное горение разряда с током до $40 \mathrm{~A}$ при давлении кислородно-аргоновой среды $0.1 \mathrm{~Pa}$, и определены условия осаждения покрытий из оксида алюминия с преимущественным содержанием альфафазы со скоростью до $6 \mu \mathrm{m} / \mathrm{h}$.

\section{Финансирование работы}

Работа выполнена при финансовой поддержке Российского научного фонда, грант № 18-19-00567.

\section{Список литературы}

[1] Anders A. // J. Appl. Phys. 2017. Vol. 121. P. 171101.

[2] Morgner H., Neumann M., Straach S., Krug M. // Surf. Coat. Technol. 1998. Vol. 108-109. P. 513-519. doi: 10.1016/S0257-8972(98)00633-1

[3] Zywitzki O., Goedicke K., Morgner H. // Surf. Coat. Technol. 2002. Vol. 151-152. P. 14-20. doi: 10.1016/S0257-8972(01)01632-2

[4] McClure G.W. // J. Appl. Phys. 1974. Vol. 45. N 5. P. 2078 2084.

[5] Борисенко А.Г., Саенко В.А., Руднищкий В.А. // ТВТ. 1999. T. 37. № 1. C. 5-12.

[6] Никитин М.М. // Известия РАН. Сер. физическая. 2010. T. 74. № 2. C. 306-312.

[7] Kaufman H.R., Robinson R.S. // AIAA J. 1982. Vol. 20. N 6. P. 745-760 doi: $10.2514 / 3.51131$

[8] Полищук П., Яриев И.М. // ТВТ. 1996. Т. 34. № 3. С. 385 391.

[9] Nerovnyi V.M., Khakhalev A.D. // J. Phys. D: Appl. Phys. 2008. Vol. 41. P. 035201 (8pp). doi: 10.1088/0022-3727/41/3/035201

[10] Гаврилов Н.В., Каменецких А.С., Третников П.В., Чукин А.В. // Письма в ЖТФ. 2017. Т. 43. Вып. 20. С. 86-94.

[11] Gavrilov N.V., Kamenetkikh A.S., Tretnikov P.V., Chuckin A.V. // Surf. Coat. Technol. 2018. Vol. 337. P. $453-460$.

doi: 10.1016/j.surfcoat.2018.01.058
[12] Магнитные ловушки / О.А. Лаврентьев. Исследование электромагнитной ловушки. Киев: Наукова думка, 1968. C. $77-147$.

[13] Гаврилов Н.В., Каменецких А.С., Спирин А.В., Чукин A.B. // ПТЭ. 2017. № 5. C. 136-141. [Gavrilov N.V., Kamenetskikh A.S., Paranin S.N., Spirin A.V., Chukin A.V. // Instrum. Exper. Techniq. 2017. Vol. 60. N 4. P. 742-747.]

[14] Schatz M. // Proceedings of the 18th International Electric Propulsion Conference, 30 September-2 October, 1985, Alexandria, VA, USA.

[15] Goebel D.M., Jameson K.K., Katz I., Mikellides I.G. // IEPC-2007-277. Proceedings of the 30th International Electric Propulsion Conference, Florence, Italy, September 17-20, 2007.

[16] Физика газового разряда / Райзер Ю.П. М.: Наука, 1992. $536 \mathrm{c}$. 